\title{
Crop Resilience to Drought With and Without Response Diversity
}

\author{
Heba H. Elsalahy ${ }^{1,2 *}$, Sonoko D. Bellingrath-Kimura ${ }^{1,3 *}$, Christina-Luise Roß ${ }^{1}$, \\ Timo Kautz ${ }^{1}$ and Thomas F. Döring ${ }^{4}$
}

\begin{abstract}
${ }^{1}$ Albrecht Daniel Thaer-Institute of Agricultural and Horticultural Sciences - Crop Science, Humboldt-University of Berlin, Berlin, Germany, ${ }^{2}$ Botany and Microbiology Department, Faculty of Science, Assiut University, Assiut, Egypt, ${ }^{3}$ Research Area "Land Use and Governance", Leibniz Centre for Agricultural Landscape Research (ZALF), Müncheberg, Germany,

${ }^{4}$ Agroecology and Organic Farming Group, University of Bonn, Bonn, Germany
\end{abstract}

OPEN ACCESS

Edited by:

Alejandra A. Covarrubias, National Autonomous University of Mexico, Mexico

Reviewed by:

Ana Wegier,

National Autonomous University of Mexico, Mexico

Ahmad M. Alqudah,

Leibniz Institute of Plant Genetics and Crop Plant Research (IPK),

Germany

${ }^{*}$ Correspondence:

Heba H. Elsalahy

Heba.elsalahy@agrar.hu-berlin.de

Sonoko D. Bellingrath-Kimura belks@zalf.de

Specialty section

This article was submitted to Plant Abiotic Stress,

a section of the journal

Frontiers in Plant Science

Received: 28 January 2020

Accepted: 06 May 2020

Published: 03 June 2020

Citation:

Elsalahy $\mathrm{HH}$,

Bellingrath-Kimura SD, ROB C-L, Kautz T and Döring TF (2020) Crop Resilience to Drought With and Without Response Diversity.

Front. Plant Sci. 11:721.

doi: $10.3389 /$ fpls.2020.00721
In the face of increasingly frequent droughts threatening crop performance, ecological theory suggests that higher species diversity may help buffering productivity by making systems more resistant through resource complementarity and more resilient through higher response diversity. However, empirical evidence for these diversity effects under drought stress has remained patchy. In two pot experiments, we explored whether mixing two legume species with a contrasting response to water availability, alsike clover (AC) and black medic (BM), promotes resistance to cumulative drought stress, and resilience of aboveground crop biomass to a transient drought event. The mixture was more productive than the average of the sole crops, and this mixture effect was higher in the non-stressed than in the drought-stressed plants. However, with six levels of constant drought intensities, the mixture effect was not consistently affected by drought level. Response diversity was evident as asynchrony of growth in the two species after the drought event, with BM re-growing faster than AC. Significant resilience to drought was observed in sole AC, i.e., without response diversity. Resilience was larger in AC than in BM and increased from 44 to 72 days after sowing (DAS). The mixture was more resilient than the average resilience of the sole crops at 72 DAS, but it was never more resilient than $\mathrm{AC}$, indicating that resilience is promoted by, but not dependent on response diversity. We conclude that crop diversity may contribute to drought resilience through growth asynchrony, but that species identity plays a crucial role in making systems more drought-resilient.

Keywords: agroecosystems, aridity, binary mixture, drought resistance, forage legumes, functional traits, monoculture

\section{INTRODUCTION}

Climate change is projected to show increasing frequency and intensity of ecosystem disturbances such as irregular rainfall patterns, including extreme drought events (IPCC, 2013; Huang et al., 2016). Drought can affect crop yield directly or through complex interactions with soil properties, nutrient availability, and temperature stress (Mariotte et al., 2018) or with soil biota such as mycorrhiza (Schimel, 2018). Two scenarios of drought may affect crop production, cumulative drought stress (Swemmer et al., 2007; NavarroCerrillo et al., 2018), and periodic (transient) drought stress (Hofer et al., 2016; Komainda et al., 2019). While plants can withstand moderate changes in total annual precipitation, increased variability in the amount of precipitation per event and in the event duration 
can substantially impair aboveground biomass production (Swemmer et al., 2007). Therefore, strategies to cope with drought in natural and managed ecosystems need to be found to maintain overall ecosystem stability, either through drought resistance, or through drought resilience, i.e., the ability to recover from drought events (Hoover et al., 2014; Hodgson et al., 2015).

Ecological theory suggests that both resistance and resilience to stress may be promoted by diversity. The underlying mechanisms behind benefits of diversity for resistance and resilience are related to the insurance hypothesis (Yachi and Loreau, 1999; Morin et al., 2014), which predicts that ecosystems with high diversity provide a buffer against environmental fluctuations (Ouédraogo et al., 2013; Oliver et al., 2015). In particular, increased plant species richness may enhance resistance through complementarity of resource use and concurrently lower niche overlap, e.g., with spatially or temporally different rooting patterns of the component species. Resilience, on the other hand, may also be enhanced by diversity. Specifically, it has been suggested that resilience critically depends on response diversity (Elmqvist et al., 2003; Mori et al., 2013). Combining species that are similar in their ability to fulfill a given function, but diverse in their responses to a particular stress may enhance the resilience of the community performance with respect to that function. Diversity within functional groups (i.e., ecological redundancy) may be critical for recovering ecosystem services after stress, as response diversity creates temporal niche differentiation allowing for compensatory dynamics among species (Loreau and de Mazancourt, 2008; Yu et al., 2016). The stress event may lead to a re-ordering of species dominance within a community, with species less affected by the stress becoming dominant because competition from the stress-affected species is relaxed (Hoover et al., 2014).

So far, however, findings have been mixed for the effect of plant diversity on both drought resistance and drought resilience. For example, while a seminal study in grassland showed that species richness promotes drought resistance (Tilman and Downing, 1994), there have also been results showing that drought resistance is not always enhanced by plant diversity, e.g., in grassland (Van Ruijven and Berendse, 2010; Lanta et al., 2012) and forest ecosystems (Grossiord et al., 2014). Also, while some studies support the diversity-resilience hypothesis (Van Peer et al., 2001; Allsion, 2004; Di Falco and Chavas, 2008; Hutchison et al., 2018), there was no positive association between response diversity and resilience in other studies (Barkaoui et al., 2016; Fischer et al., 2016; Bhaskar et al., 2018). Further, research on the diversity-resilience relationship has so far mostly focused on permanent grasslands or forests, concentrating on longer-term, i.e., multiannual, effects through shifts in species composition (Tilman and Downing, 1994; Ouédraogo et al., 2013; Fischer et al., 2016; Hofer et al., 2016). In contrast, evidence for effects of response diversity on resilience remains scarce for arable cropping systems, where shorter-term, i.e., within-season effects are more relevant than year-to-year resilience, and where planned species diversity is most often much lower than in grasslands.

Therefore, we studied the effect of plant diversity on drought resistance and resilience in an arable cropping context, using the simplest possible design, by testing sole crops of two different plant species against their binary mixture. We chose two legume species, alsike clover (AC; Trifolium hybridum L.) and black medic (BM; Medicago lupulina L.), thus both belong to the same functional group. We only varied species richness and no other parameter of diversity to ensure that differences in response diversity were as large as possible. Legumes play a vital role in arable cropping systems because of their ability to fix atmospheric nitrogen, but also because they increase soil organic matter levels, facilitate soil nutrient circulation and suppress weeds (Döring et al., 2013; Stagnari et al., 2017). While both species are also found in permanent grassland, they are frequently used as shortterm green manures in arable systems to increase soil fertility, to attract beneficial insects or as living mulches to suppress weeds (Döring et al., 2013; Elsalahy et al., 2019). The selected species are characterized by various contrasting traits. BM is a fast-growing perennial well-adapted to warm and dry areas (Chapman et al., 1990; Döring et al., 2013; Elsalahy et al., 2019; FAO, 2019); it has a short-medium and spreading growth habit forming good ground cover (Floulds, 1978). Conversely, AC is a slow-growing drought-sensitive perennial, best adapted to cool and wet areas (Sheaffer et al., 2003; Döring et al., 2013) which has an upright growth habit with a single crown from which multiple florets are produced (Frankow-Lindberg et al., 2009; Storkey et al., 2015).

We used two pot experiments to quantify resistance and resilience of the two legumes, sown as sole crops and in an equiproportional mixture. Specifically, we aimed to test if the mixture shows higher resilience and resistance to drought stress than the two sole crops. Drought resistance was quantified in response to cumulative drought (CD) with six levels of drought intensities whereas resilience was quantified by comparing plants exposed to a single transient drought event (DE) to non-stressed plants. Our key hypotheses were: (1) The two species differ in their drought resistance and resilience. (2) Because of resource complementarity, the mixture is more drought-resistant than the sole crops. (3) Because of response diversity, the mixture is more drought-resilient than the sole crops.

\section{MATERIALS AND METHODS}

\section{General Set-Up}

Two pot experiments were conducted at the Humboldt University experimental station at Berlin-Dahlem in a greenhouse protected on all sides with a wire mesh (25.4 $\times 25.4 \mathrm{~mm}$ clear opening, $3.18 \mathrm{~mm} \varnothing$ wire). The mesh size allowed insects, wind, and temperature to be inside the greenhouse as in the surrounding field but prevented any larger animals from entering. The greenhouse roof was covered with polycarbonate plastic panels (16 $\mathrm{mm}$ triple wall) transmitting $76 \%$ of ambient light.

In both experiments, three mixture treatments were used, a sole crop of AC (cv. Dawn), a sole crop of BM (cv. Ekola), and a 1:1 mixture. The seeds were bought from Deutsche Saatveredelung AG (DSV) and Camena Samen, Germany for $\mathrm{AC}$ and $\mathrm{BM}$, respectively. The selection of $1: 1$ mixing ratio is based on two field experiments conducted over 2 years, where 
we tested the two species at five mixing ratios of AC:BM (100:0, $67: 33,50: 50,33: 67$, and 0:100) sown at three seed densities representing 50,100 , and $150 \%$ of the recommended seed density. The results showed that the equiproportional mixture of the two species had a stronger (or more consistent) positive mixture effect in comparison with the other mixing ratios (Elsalahy et al., 2019). Seed density was 24 seeds per pot, with seeds of the two species being spatially alternated in the mixture to ensure maximal interspecific interaction. Any emerged weed seedlings were removed daily from the pots. Precise irrigation was facilitated by using a dispenser (Rotilabo ${ }^{\circledR}$-Dispenser $20-100 \mathrm{ml}$, accuracy $1 \mathrm{ml}$, by Roth, Germany).

In both experiments, the plants were sampled by cutting them ca. $0.5 \mathrm{~cm}$ above the soil surface. In the mixture, the harvested material of the two species was manually separated and bagged separately into transparent microperforated plastic bags, made of SM570Y film (Cryovac ${ }^{\circledR}$, Sealed Air Corporation, Elmwood Park, NJ, United States) and oven-dried (Thermo Scientific Heraeus UT 6760 , Germany) at $65^{\circ} \mathrm{C}$ for $72 \mathrm{~h}$ to obtain constant weight.

\section{Drought Resistance Experiment}

The experiment was started on 1st June 2016 and run for 50 days to simulate the effect of cumulative drought. Six drought intensities were established with varied levels of water holding capacity (WHC) of the soil. The average daily temperature during the period of the experiment was $18.2^{\circ} \mathrm{C}$, ranging from 15.1 to $27.2^{\circ} \mathrm{C}$. The average daily radiation was $20.0 \mathrm{MJ} \mathrm{m}^{-2} \mathrm{~d}^{-1}$, ranging from 6.1 to 30.4 (Agricultural Climatology of the Hu-Berlin, 2018).

One day before sowing, square pots $(12 \times 12 \times 19 \mathrm{~cm})$ were filled with $3430 \mathrm{~g}$ substrate collected from the top soil (upper $\sim 15 \mathrm{~cm}$ ) of a non-cropped bare field at the experimental station of Humboldt University of Berlin in Dahlem $\left(52^{\circ} 28^{\prime} \mathrm{N}, 13^{\circ}\right.$ $18^{\prime} \mathrm{E}, 51 \mathrm{~m}$ asl). The soil, a sandy clay loam (Brady and Weil, 2002), had a pH of 6.3, organic matter content of $1.24 \%$, nitrogen content of $0.13 \%$, and nutrient contents per $\mathrm{kg}$ soil of $251 \mathrm{mg}$ P, $90 \mathrm{mg} \mathrm{K}, 52 \mathrm{mg} \mathrm{Mg}, 1471 \mathrm{mg} \mathrm{Ca}$, and $7354 \mathrm{mg} \mathrm{Fe}^{3+}$. Soil WHC was measured in three replicates and calculated following Nguyen and Lehmann (2009).

The experimental design was a two-factorial randomized complete block design in four replicates with the factor diversity (called DIV) comprising three diversity treatments (two monocultures and one mixture), and the drought factor (called $C D$ ), with six levels of cumulative drought intensity (see below). Each block contained 18 pots and one control pot without plants to calculate the daily evaporated water (Supplementary Figure S2).

On the day of sowing, $478 \mathrm{ml}$ distilled were added to each pot to moisten the soil and to facilitate placing the seeds in fixed distances without silting up the soil surface. Seeds were sown at a depth of $0.5 \mathrm{~cm}$ with a handmade wooden seed stamp in a design of $6 \times 4$ to allow $2 \mathrm{~cm}$ space between sown seeds. Three days later, an equal amount of water was added to all treatments to compensate for evaporation and ensure optimum conditions for germination in all treatments by keeping WHC at $\sim 90 \%$ before starting the different irrigation regimes.
One week after sowing, differentiated irrigation was initiated, creating six different levels. The average weight of the control pots (without plants) was determined to calculate the amount of evaporated water. This amount was then given to the $100 \%$ WHC level and reduced to $85,70,55,40$, and $25 \%$ of WHC (Supplementary Figure S1A). Three weeks later, an additional amount of water was added to compensate for transpiration. To keep the relative differences fixed between the treatments, the added amounts to compensate transpiration was summed to the evaporated water and reduced gradually according to the previously determined levels. E.g., when the pots were irrigated with $200 \mathrm{ml}$ for evaporation and $100 \mathrm{ml}$ for transpiration, the sum of $300 \mathrm{ml}$ represented $100 \%$ WHC and was reduced accordingly for the other levels. Cover crop aboveground biomass (CCB) was harvested once at the end of the experiment.

\section{Drought Resilience Experiment}

The experiment was started on 26th June 2017 and was run for 72 days. The average daily temperature during the period of the experiment was $18.2^{\circ} \mathrm{C}$, ranging from 13.5 to $24.6^{\circ} \mathrm{C}$ and the average daily radiation was $13.5 \mathrm{GS} \mathrm{MJ} \mathrm{m} \mathrm{m}^{-2} \mathrm{~d}^{-1}$, ranging from 1.2 to 24.5 (Agricultural Climatology of the Hu-Berlin, 2018).

Round pots ( $3.5 \mathrm{~L}, \varnothing 12 \times 25 \mathrm{~cm}$ height) were filled with soil collected from the top-soil (upper $\sim 15 \mathrm{~cm}$ ) of a non-cropped bare field at the experimental field station of the Humboldt University of Berlin in Dahlem. The soil was sandy loam (Brady and Weil, 2002) with a pH-value of 6.3 , organic matter content of $0.72 \%$, nitrogen content of $0.09 \%$, and nutrient contents per $\mathrm{kg}$ soil of $121 \mathrm{mg} \mathrm{P}, 83 \mathrm{mg} \mathrm{K}, 37 \mathrm{mg} \mathrm{Mg}, 1242 \mathrm{mg} \mathrm{Ca}$, and $5044 \mathrm{mg} \mathrm{Fe}^{3+}$. The pots were filled with the soil and covered with a circular filter paper and $500 \mathrm{ml}$ of tap water was poured carefully onto the filter paper. Soil WHC was measured as reported above.

The experimental design was a three-factorial randomized complete block design in five replicates with three diversity treatments (called DIV; two monocultures and one mixture), two drought event treatments (called $D E$, non-stressed and drought-stressed), and five prospective harvest times (called Har, H1 to H5). Each block contained 30 pots and one control pot without plants to determine daily evaporated water (Supplementary Figure S3).

One day before sowing, the pots were filled with $3392 \mathrm{~g}$ of soil. On the next day, the soil was moistened with $25 \mathrm{ml}$ water after placing a filter paper on the soil surface to avoid silting up. Then, the seeds were manually placed on top of the wet substrate in a regular pattern, using a sowing stencil to mark the seeds' positions. Immediately after placing the seeds, $108 \mathrm{~g}$ of loosely dry soil was spread evenly on top of the soil surface to cover the sown seeds. The filter paper was again placed on the top of the soil surface while adding $500 \mathrm{ml}$ of water to adjust WHC at $\sim 90 \%$. Afterward, until 22 DAS, all non-stressed plants and stressed plants were irrigated equally and received an amount of cumulative applied water equal to $0.98 \mathrm{~L} \mathrm{pot}^{-1}$ (Supplementary Figure S1B).

At 23 DAS (H1), a drought event was started for 14 days. During the drought event, the stressed plants received 33\% of the water added to the non-stressed plants. At 37 DAS (H2), the drought stress was released by re-watering the non-stressed 
plants and stressed plants daily with the same amounts of water. Plant recovery, namely plant growth after the drought event was evaluated at 44, 58, and 72 DAS. At each of the five harvest times, different pots were harvested to evaluate the temporal development of CCB production over the course of the experiment.

\section{Calculation of Indices}

In both experiments, water use efficiency (WUE, in g DM $L^{-1}$ ) was determined by using Equation (1) (Komainda et al., 2019).

$$
\mathrm{WUE}=b_{i} / w_{i}
$$

where $b_{\mathrm{i}}$ is CCB in g per pot, produced at harvest $\mathrm{i}$, and $w_{\mathrm{i}}$ is the irrigation water in $L$ per pot cumulated until the harvest $i$.

In the resilience experiment, crop growth rate (CGR in $\mathrm{g} \mathrm{m}^{-2}$ $\mathrm{d}^{-1}$ ), defined as the CCB per unit ground area per unit time ( $g$ $\mathrm{m}^{-2}$ day $^{-1}$ ) was calculated by using Equation (2) (Poorter, 1989).

$$
\mathrm{CGR}_{\mathrm{i}}=\left(b_{i}-b_{i-1}\right) /\left[A\left(t_{i}-t_{i-1}\right)\right]
$$

where $b_{\mathrm{i}}$ and $b_{\mathrm{i}-1}$ are dry matter in $\mathrm{g}$ per pot at the end and beginning of a time interval, respectively, i.e., at harvest $i$ and $i-1$, thus, $t_{\mathrm{i}}-t_{\mathrm{i}-1}$ is the time interval in days between two consecutive harvest times; and $A$ is the ground area of the pot in $\mathrm{m}^{2}$.

To quantify the effect of the mixture in comparison to the monocultures, land equivalent ratio (LER) and partial LER (PLER) of the two species were calculated for the CCB ( $g$ $\left.\mathrm{DM} \operatorname{pot}^{-1}\right)$. The LER of a mixture measures the relative land area that is required for the crop monocultures to produce the same $\mathrm{CCB}$ as observed in the mixture; it was calculated as the sum of the PLERs of the two species in the mixture by using Equation (3) (Mead and Willey, 1980).

$$
\mathrm{LER}=\text { PLER }_{\mathrm{AC}}+\text { PLER }_{\mathrm{BM}}=\frac{\mathrm{b}_{\mathrm{AC} \_ \text {mix }}}{\mathrm{b}_{\mathrm{AC} \_ \text {mono }}}+\frac{\mathrm{b}_{\mathrm{BM} \_ \text {mix }}}{\mathrm{b}_{\mathrm{BM} \_ \text {mono }}}
$$

where $\mathrm{b}_{\mathrm{AC} \_ \text {mono }}$ and $\mathrm{b}_{\mathrm{BM} \_ \text {mono }}$ are the biomass of species $\mathrm{AC}$ and $\mathrm{BM}$ in monoculture and $\mathrm{b}_{\mathrm{AC} \_ \text {mix }}$ and $\mathrm{b}_{\mathrm{BM} \_ \text {mix }}$ are the biomass of each species in the mixture. An LER $>1$ indicates that the mixture makes more efficient use of the land and has an advantage over the monoculture. Partial LERs show the relative competitive abilities of each species in the mixture and can be interpreted as a measure for the contribution of each species according to its density ratio in the mixture relative to the monoculture.

For CCB, WUE, and CGR, the absolute mixture effect (AME) was calculated as the difference between the observed value in the mixture and the average values of the two monocultures (Equation 4). For the same variables, the relative change in response to stress (Hofer et al., 2016) was calculated by using Equation (5).

$$
\mathrm{AME}=y_{\text {mix }}-\left(y_{A C}+y_{B M}\right) / 2
$$

Change in variable $y(\%)=100^{*}\left(\mathrm{y}_{\text {stressedplants }} / \mathrm{y}_{\text {non-stressed plants }}-1\right)$
To quantify resilience, we used Equation (6) according to Orwin and Wardle (2004).

$$
r=\frac{2\left|D_{0}\right|}{\left(\left|D_{0}\right|+\left(\left|D_{x}\right|\right)\right.}-1
$$

where $D_{0}$ is the difference between the biomass of the nonstressed plants and the stressed plants at the end of the drought event at $\left(t_{0}\right)$ and $D_{x}$ is the difference between the non-stressed plants and the stressed plants at the time point $t_{x}$ chosen to measure resilience (harvests $\mathrm{H} 3, \mathrm{H} 4$, and $\mathrm{H} 5$ ). This resilience index $r$ is bounded by -1 and +1 , with maximal resilience at +1 . This index is standardized by the amount of change initially caused by the drought $\left(D_{0}\right)$, as this determines the state from which it has to recover.

\section{Statistical Analysis}

In the drought resistance experiment, CCB and WUE were nonnormally distributed according to the Shapiro-Wilk test and the variances between the groups were homogeneous according to Levene's test in the car R-package (John and Weisberg, 2011). To satisfy normality criteria a generalized linear model was used with quasipoisson error distribution and a log link function in the nlme package (Pinheiro et al., 2018). The model included two independent variables representing $D I V$ and $C D$, and their interaction $D I V \times C D$. Block effect was removed from the model because it did not show improvement in the model according to Akaike's information criterion (AIC) (Burnham et al., 2011). Following ANOVA, Tukey's HSD test at $\alpha=0.05$ was used to determine the significance of differences among the treatments' mean values at a given irrigation regime by using the Agricola Rpackage (De Mendiburu, 2019).

In the resilience experiment, CCB, WUE, and CGR at the different harvest times were evaluated with ANOVA. In a first step, a model was used with DIV,DE, Har and all possible interactions between the three factors. As a further step, to provide an easier interpretation to the performance of the treatment independent of the drought stress event, the data of non-stressed plant and stressed plants were analyzed separately as submodels with two factors (DIV, Har, and DIV $\times$ Har $)$. In each sub-model, the normality of residuals was checked. Block effect was almost significant and showed an improvement in the model according to AIC (Burnham et al., 2011); therefore it was considered in all submodels to create consistent comparison among the models. After ANOVA, Tukey's HSD test at $\alpha=0.05$ was used to determine the significance of differences among the mean values of the treatments at a given harvest time by using the Agricola package (De Mendiburu, 2019). The significance of LER above one was tested by using two-sided Welch's $t$-tests against 1 . All statistics were performed using $\mathrm{R}$ (version 3.6.1) with $\mathrm{R}$ studio (version 1.1.463) (R Core Team, 2019).

\section{RESULTS}

\section{Diversity and Drought Resistance}

In the drought resistance experiment, the factors $D I V, C D$, and $D I V \times C D$ significantly affected crop biomass. A level of $25 \%$ 

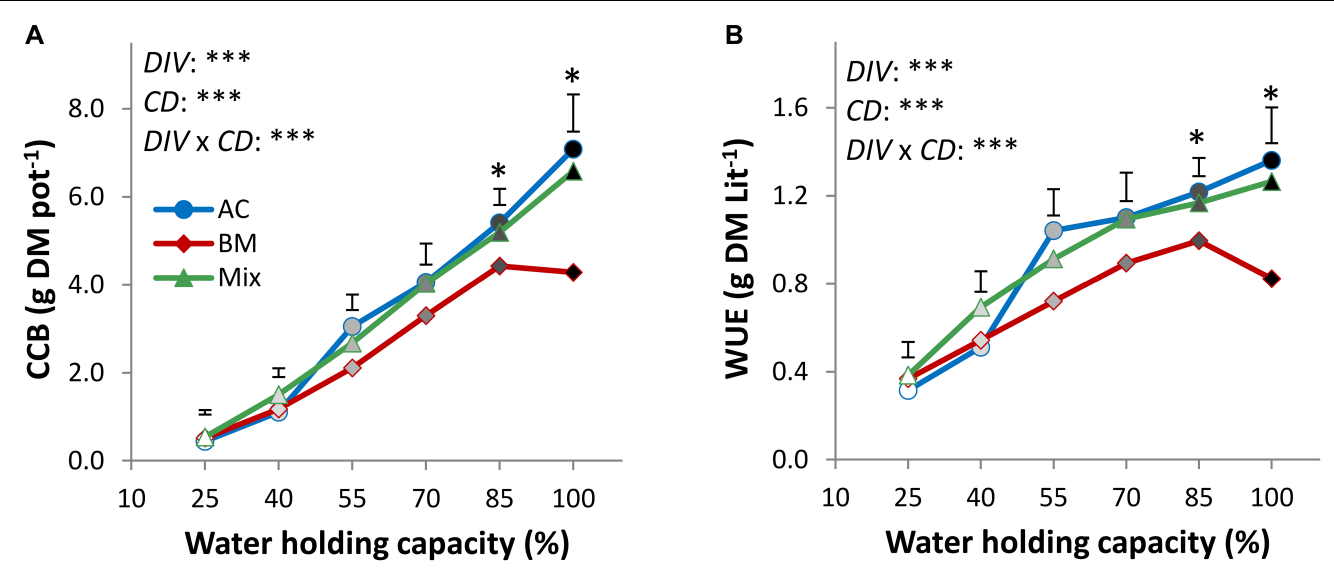

FIGURE 1 | Cover crop aboveground biomass (CCB, dry matter; A) and water use efficiency (WUE; B) of alsike clover (AC) and black medic (BM) in monocultures and a 1:1 mixture of the two species (Mix) in response to six intensities of cumulative drought $(100,85,70,55,40$, and $25 \%$ WHC) visualized in black gradient color. Vertical bars represent Tukey's HSD test $(p<0.05)$ at a given WHC (\%) of $n=4$. Asterisks above the vertical bars indicate significant differences among the mean of the monocultures and the mixture at each drought intensity (WHC; \%) based on one-way ANOVA at $P<0.05$. However, asterisks next to the factors $D I V$, CD, and $D I V \times C D$ indicate significant effects based on ANOVA results of the generalized linear model; ${ }^{* * *} P<0.001,{ }^{*} P<0.05$

WHC reduced CCB by $93.8,87.9$, and $91.8 \%$ in $\mathrm{AC}_{\text {mono }}, \mathrm{BM}_{\text {mono }}$, and the mixture, respectively, compared to full irrigation (Figure 1A and Supplementary Table S1), thus revealing slightly higher drought resistance in $\mathrm{BM}_{\text {mono }}$ than in $\mathrm{AC}_{\text {mono. The }}$ $\mathrm{AC}_{\text {mono }}$ produced more $\mathrm{CCB}$ than the other treatments from 55 to $100 \% \mathrm{WHC}$, with significantly higher biomass than $\mathrm{BM}_{\text {mono }}$ by 37.5 and $39.5 \%$ at 85 and $100 \%$ WHC, respectively. The mixture biomass was not significantly different from $\mathrm{AC}_{\text {mono }}$ at any drought intensity but was significantly higher than $\mathrm{BM}_{\text {mono }}$ by 32.7 and $34.9 \%$ at 85 and $100 \%$ WHC, respectively.

The cumulative drought effect on WUE showed a similar trend as CCB in all treatments, with a reduction by $76.9,55.3$, and $69.6 \%$ in $\mathrm{AC}_{\text {mono }}, \mathrm{BM}_{\text {mono, }}$, and the mixture, respectively, at $25 \%$ WHC compared to full irrigation (Figure $\mathbf{1 B}$ and Supplementary Table S2), again confirming higher drought resistance in $\mathrm{BM}_{\text {mono }}$ than in $\mathrm{AC}_{\text {mono. }} \mathrm{AC}_{\text {mono }}$ was higher in WUE than the other treatments at drought intensity from 55 to $100 \%$ WHC. Specifically, at 85 and $100 \%$ WHC, the WUE of $\mathrm{AC}_{\text {mono }}$ was significantly higher than $\mathrm{BM}_{\text {mono }}$ by 85.9 and $88.4 \%$, respectively, but it was not different from that of the mixture.

The LER was $>1$ at the different drought intensities, but this was only significant at $40 \%$ WHC (Figure 2A). Notably, there was no consistent directional effect of drought intensity on LER. Drought intensity did not significantly correlate with LER $(r=0.29, P=0.57, d f=4)$, nor with the AME $(r=0.07$, $P=0.90, d f=4)$. In the mixture, BM was dominant and at drought intensities showed PLER BM $_{\text {above } 0.5 \text {, with a minimum }}$ of 0.58 at $70 \%$ WHC and a maximum of 0.89 at $40 \%$ WHC. Thus, there was also no trend of PLER $\mathrm{BM}$ along the drought intensities. Conversely, PLER $\mathrm{AC}_{\mathrm{C}}$ was lower than 0.5 at most of the drought intensities.

\section{Diversity and Drought Resilience}

All mixtures, both when non-stressed and when droughtstressed, showed LER $>1$ after $\mathrm{H} 2$ but this was not consistently significant (Figure 2B). In the non-stressed plants, the increase in LER was significantly larger than one only at $\mathrm{H} 2$ and $\mathrm{H} 3$ while this was the case in the drought-stressed plants only at H4 and H5. A trend was observed in the PLERs over time independent of the drought event, where BM dominated at the early stages of growth (points moving toward higher PLER $\mathrm{BM}$ and lower PLER $_{A C}$ over time) whereas AC gradually contributed relatively more to the mixture at later stages (points moving back toward lower PLER $\mathrm{BM}$ and higher PLER $\mathrm{AC}$ ).

In the drought resilience experiment, the factors DIV, Har, and DIV $\times$ Har significantly affected CCB, WUE and CGR in the non-stressed and drought-stressed plants (Figure 3 and Supplementary Tables S3, S4). In the non-stressed plants from $\mathrm{H} 2-\mathrm{H} 5$, the $\mathrm{AC}_{\text {mono }}$ produced more $\mathrm{CCB}$ than $\mathrm{BM}_{\text {mono }}$ up to $28.8 \%$, and in the stressed plants from $\mathrm{H} 4-\mathrm{H} 5$ up to $36.2 \%$ (Figures 3A,B). The mixture biomass was not significantly different from $\mathrm{AC}_{\text {mono }}$ at any of the harvest times.

The effect of the DE on WUE at $\mathrm{H} 1$ showed a similar trend as $\mathrm{CCB}$ in all diversity treatments where $\mathrm{AC}_{\text {mono }}$ was significantly higher than $\mathrm{BM}_{\text {mono }}$ at $\mathrm{H} 5$ up to 40.8 and $36.4 \%$ in the non-stressed plants and drought-stressed plants, respectively (Figures 3C,D).

The dynamics of CGR in the non-stressed plants showed that $\mathrm{AC}_{\text {mono }}$ reached a peak at $\mathrm{H} 3$ which was by $40.1 \%$ higher than CGR of $\mathrm{BM}_{\text {mono }}$, but did not differ from the Mix (Figure 3E). However, in the stressed-plants, $\mathrm{AC}_{\text {mono }}$ reached a peak of CGR at $\mathrm{H} 4$ with significantly higher values than $\mathrm{BM}_{\text {mono }}$ and the Mixture by 54.0 and 25.6\%, respectively (Figure 3F).

The absolute mixture effect on CCB, i.e., the difference between the observed value in the mixture and the average value of the sole crops, increased over time and tended to be higher in the non-stressed than in the drought-stressed plants, especially at $\mathrm{H} 3$ and H4 (Figure 4A). Similar trends were observed for WUE and CGR (Figures 4B,C).

Further data analysis was performed on the effect of the drought event, measured as the relative difference between drought-stressed and non-stressed plants to understand the 

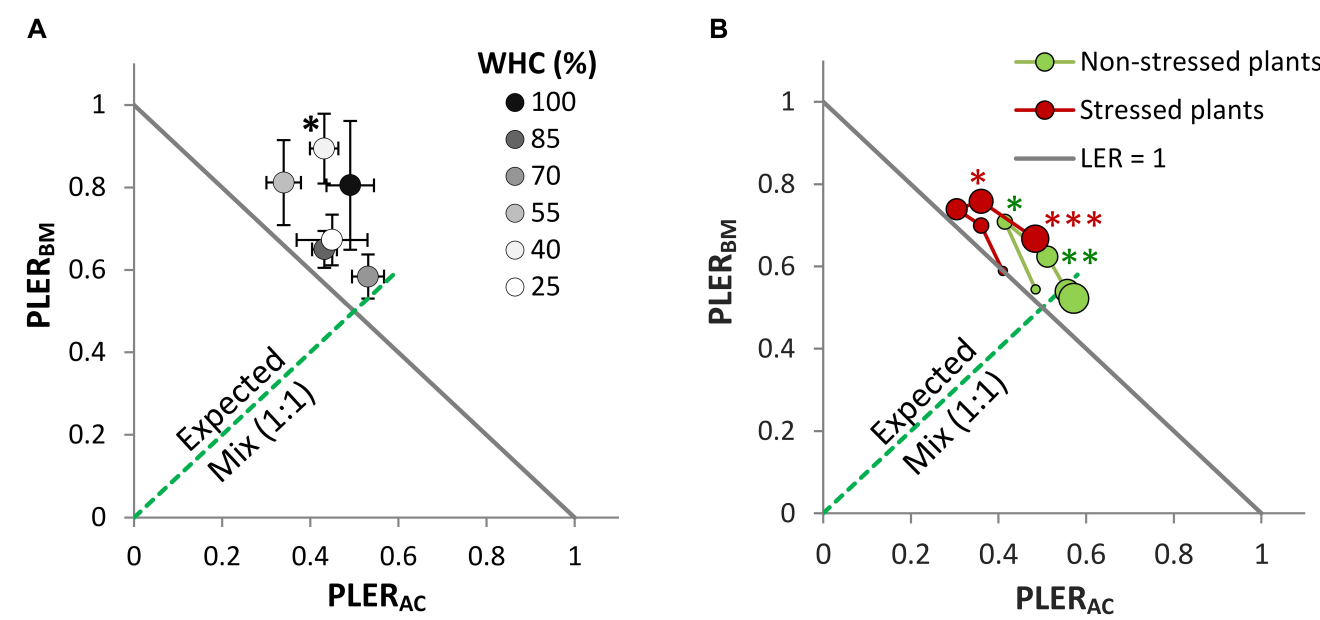

FIGURE 2 | Partial Land equivalent ratio of alsike clover (PLER $\mathrm{AC}_{\mathrm{C}}$ ) and black medic (PLER $\mathrm{BM}$ ) in a binary mixture of the two species (1:1) in two experiments simulating two drought scenarios: (1) cumulative drought (A) with six drought intensities as in Figure 1, and (2) a drought event (B) with two treatments of non-stressed plants (green symbols) and the stressed plants (red symbols). Successive harvest times are visualized by increasing symbol size. The solid gray line corresponds to a land equivalent ratio $=1\left(\mathrm{LER}=\mathrm{PLER}_{\mathrm{AC}}+\mathrm{PLER}_{\mathrm{BM}}\right)$. The broken green line represents the expected PLER for the mixture. Asterisks above some data points represent a significant increase in LER $>1(P<0.05)$ according to Welch's $t$-test; ${ }^{* * *} P<0.001,{ }^{* *} P<0.01,{ }^{*} P<0.05$.

dynamics of biomass, WUE, and CGR. Shortly after the event, drought affected all three variables less in $\mathrm{BM}_{\text {mono }}$

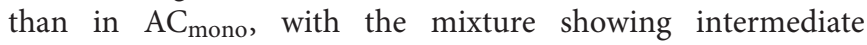
values (Figures $4 \mathrm{D}-\mathrm{F}$ ). With regard to $\mathrm{CGR}, \mathrm{BM}_{\text {mono }}$

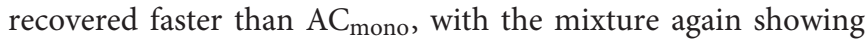
intermediate behavior (Figure 4F). At the final harvest, however, differences in the drought effect on CGR were not significant among treatments.

The resilience index, quantifying the capacity of biomass to recover after the drought event, increased over time and showed a significant diversity treatment effect, which varied over time (Figure 5A). At H3, 1 week after cessation of the drought event, recovery was negative in sole $\mathrm{AC}$ and in the mixture, but not different from zero in $\mathrm{BM}_{\text {mono. While at } \mathrm{H} 4 \text { no significant }}$ differences were observed in the recovery among the diversity treatments, a significantly higher resilience index was found for AC than for BM at H5. The absolute mixture effect of the resilience index increased over time and was significantly positive at the last harvest, i.e., the mixture recovered more fully than expected from the average recovery of the two-component monocultures (Figure 5B).

\section{DISCUSSION}

\section{Effects of Species Identity and Mixing on Drought Resistance}

Our drought resistance experiment confirmed previous research (Döring et al., 2013; Storkey et al., 2015; Elsalahy et al., 2019; Komainda et al., 2019) that BM is more drought-resistant than AC. Relative to the maximum biomass potential, which was higher in $\mathrm{AC}$ than in BM, the biomass under constant drought conditions was similar in both species, so that the relative biomass-reducing effect of drought was stronger in
AC than in BM (Figure 1A). However, differences between the species were smaller than expected - in fact, both species had a relatively strong capacity to tolerate drought, possibly because the slowly imposed constant drought triggered drought stress memory in the plants to adjust structure, metabolism, and function to withstand drought (Fleta-Soriano and MunnéBosch, 2016). This would explain why AC was able to perform similarly to BM under extreme drought (Figure 1A) despite AC's reported drought sensitivity (Chapman et al., 1990; Sheaffer et al., 2003). Under conditions of $100 \%$ WHC, AC produced more biomass than $\mathrm{BM}$, which was anticipated as $\mathrm{AC}$ is known to be well-adapted to wet conditions (Döring et al., 2013). $\mathrm{BM}$, on the other hand, was negatively affected at $100 \% \mathrm{WHC}$, confirming that BM grows better in well-drained soil while insufficient oxygen in water-saturated soil impairs its growth (Döring et al., 2013; Elsalahy et al., 2019). Further measurements on root biomass showed no significant difference between the two species. However, assessing the root:shoot ratio of both species showed potentially different plant-specific strategies of resource uptake in response to drought. Remarkably, BM showed no significant difference in root:shoot ratio at the different cumulative drought intensities, suggesting that BM may resist drought without altering root:shoot allocation. However, the root:shoot ratio of AC showed a significant difference by responding to drought intensity, with large differences between the well-watered plants at $100 \% \mathrm{WHC}$ and the extreme drought treatment at $25 \% \mathrm{WHC}$. This observation suggests that $\mathrm{AC}$ as a slow-growing species may exhibit high phenotypic plasticity against cumulative drought (Supplementary Figure S4). More importantly, we did not find any consistent mixture effect on drought resistance, in line with previous research (Van Ruijven and Berendse, 2010; Lanta et al., 2012; Grossiord et al., 2014). Although WUE in the mixture was increased in comparison with the average WUE of the monocultures (Figure 1B), confirming 

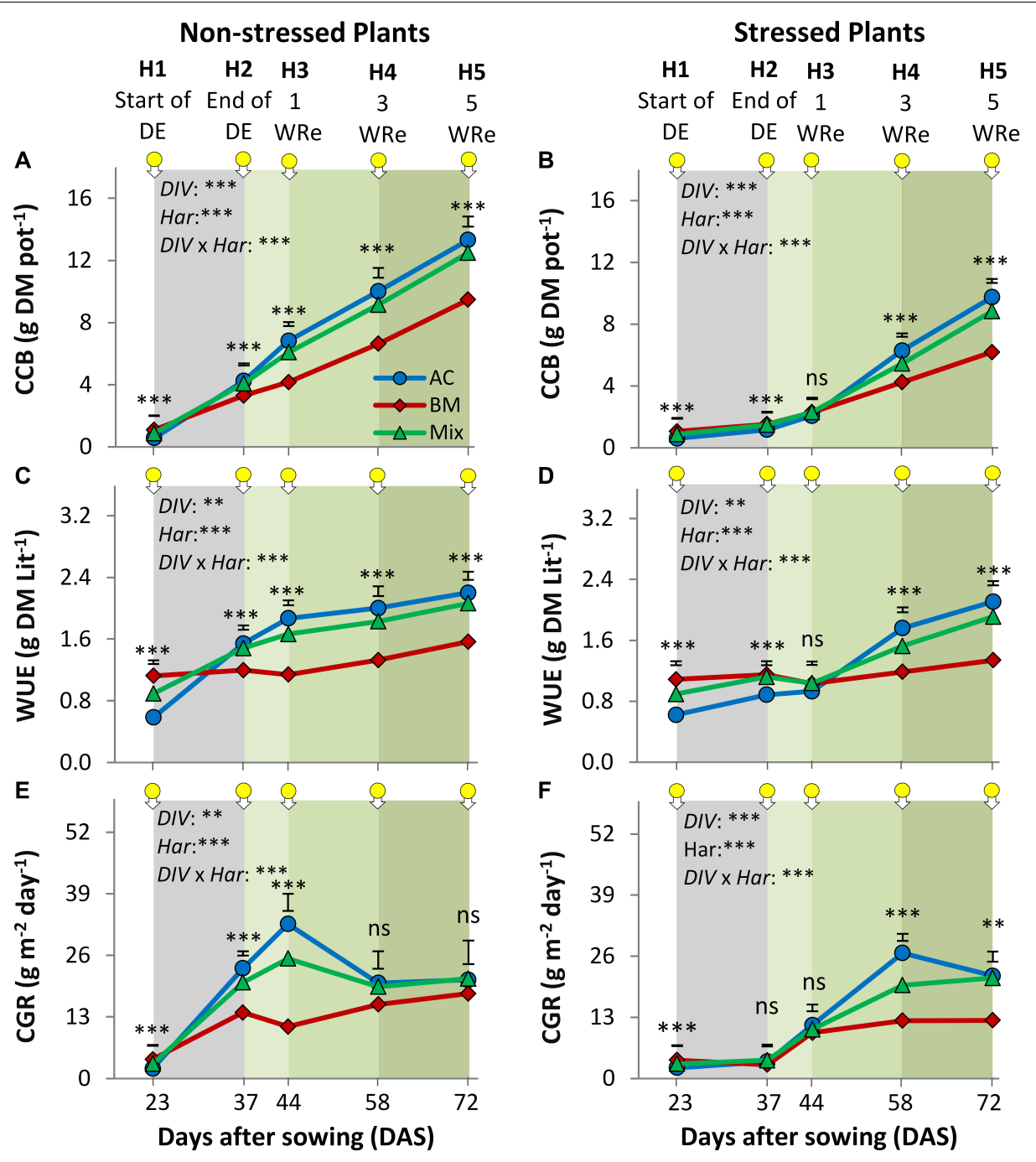

FIGURE 3 | Cover crop aboveground biomass (CCB; A,B), water use efficiency (WUE; C,D), and crop growth rate (CGR; E,F) of alsike clover (AC), black medic (BM) in monocultures and a 1:1 mixture of the two species (Mix). The non-stressed plants $(\mathbf{A}, \mathbf{C}, \mathbf{E})$ and stressed plants $(\mathbf{B}, \mathbf{D}, \mathbf{F})$ were harvested five times indicated by the downward arrows tagged with yellow small circles. The stressed plants were subjected to a drought event (DE; gray shaded) for 14 days. The green gradient color represents weeks of recovery (WRe) after rewatering. Vertical bars represent Tukey's HSD test $(P<0.05)$ at a given harvest time $(n=5)$. Asterisks above the vertical bars indicate significant differences among the mean of the monocultures and mixture at each harvest time based on one-way ANOVA at $P<0.05$. However, asterisks next to the factors DIV, Har, and DIV $\times$ Har indicate significant effects based on ANOVA results of the generalized linear model; ${ }^{* *} P<0.001,{ }^{* *} P<0.01$, ns, not significant.

earlier results (Mariotte et al., 2013), the relative advantage of the mixture over the monocultures was not affected by drought intensity (Figure 2A). We see two potential reasons for this lack of association between drought intensity and mixture effect.

First, mixture effects are expected to be driven by reduced competition among individual plants, so that total resource use is greater in the mixture than in the monocultures (Bedoussac et al., 2015). In our case, however, competition between plants may just have been relatively independent of water availability, so that any benefits of reduced competition in the mixture could not play out differentially across the levels of drought intensity. Under conditions of constant low water availability, plant growth was restricted and therefore the zone of influence of these plants would have been small (Schwinning and Weiner, 1998), whereas full irrigation led to expanded plant size and thereby to an increased zone of influence. Thus, under constant drought the effects of reduced resource availability (leading to increased competition among plants) and reduced plant size (leading to decreased competition) may partly have canceled out, so that any competition related effects of mixing would be little affected by drought intensity.

Second, complementarity for water use may be possible through different spatiotemporal growth patterns of the two species, i.e., asynchronous root development, but as we harvested the plants only once we potentially missed the dynamic interaction between the plants, in particular any asynchrony. 


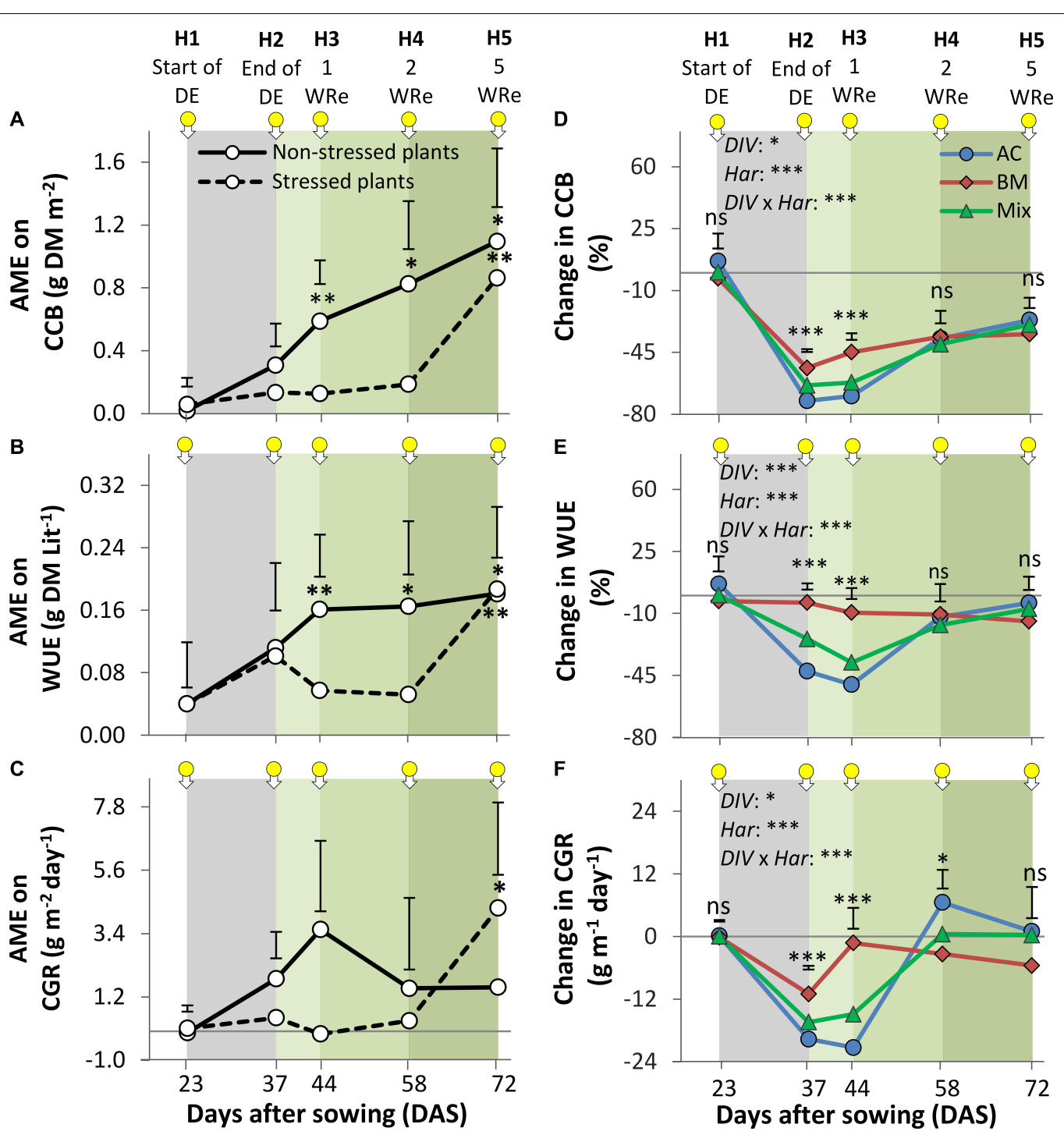

FIGURE 4 | Absolute mixture effect (AME) on cover crop aboveground biomass (CCB; A), water use efficiency (WUE; B), and crop growth rate (CGR; C) of alsike clover (AC), black medic (BM) in monocultures and a 1:1 mixture of the two species (Mix). Mixture effect = the estimated value in mixture - the estimated value in average of monocultures. Positive values indicate positive mixture effect. Change in the CCB (D), WUE (E), and CGR (F) (see Equation 5). The plants were harvested at five times indicated by the downward arrows tagged with yellow small circles. The gray shaded area indicates the duration of a drought event and the green gradient color represents weeks of recovery (WRe) after rewatering. In (A-C), the non-stressed plants and stressed plants are visualized in solid and broken lines, respectively, the vertical bars represent LSD test $(p<0.05)$ at a given harvest time $(n=5)$ and the asterisks indicate significant mixture effects above 0 according to Welch's $t$-test. In (D-F) The vertical bars represent Tukey's HSD test $(p<0.05)$ at a given harvest time $(n=5)$. Asterisks above the vertical bars indicate significant differences among the mean of the monocultures and mixture at each harvest time based on one-way ANOVA at $P<0.05$. However, asterisks next to the factors $D I V$, Har, and DIV $\times$ Har indicate significant effects based on ANOVA results of the generalized linear model; ${ }^{* * *} P<0.001,{ }^{*} P<0.05$, ns, not significant.

Also, spatial complementarity may be limited in a pot experiment where root space is restricted, though such restriction may also be partly the case under field conditions, e.g., due to soil compaction.

\section{Effects of Species Identity and Mixing on Drought Resilience}

In line with previous findings (Van Peer et al., 2001; Allsion, 2004; Di Falco and Chavas, 2008; Hutchison et al., 2018), we found that mixing species promoted resilience (Figure 5B). Notably, however, we also found that resilience to drought is possible with only one species present (Figure 5A), i.e., without any response diversity. This is in contrast to previous statements emphasizing that resilience requires response diversity (Tilman and Downing, 1994; Mori et al., 2013). Yet from an evolutionary perspective, individual plants will benefit from the ability to recover after a drought event, so any physiological mechanism that allows faster or fuller recovery will be selected for. It is therefore expected that even in a plant monoculture, resilience to drought will occur. The basis for recovery will be reserves built up during the pre-stress period, e.g., in the roots. In addition, an indirect mechanism may lead to a high resilience index in both single species and mixed 

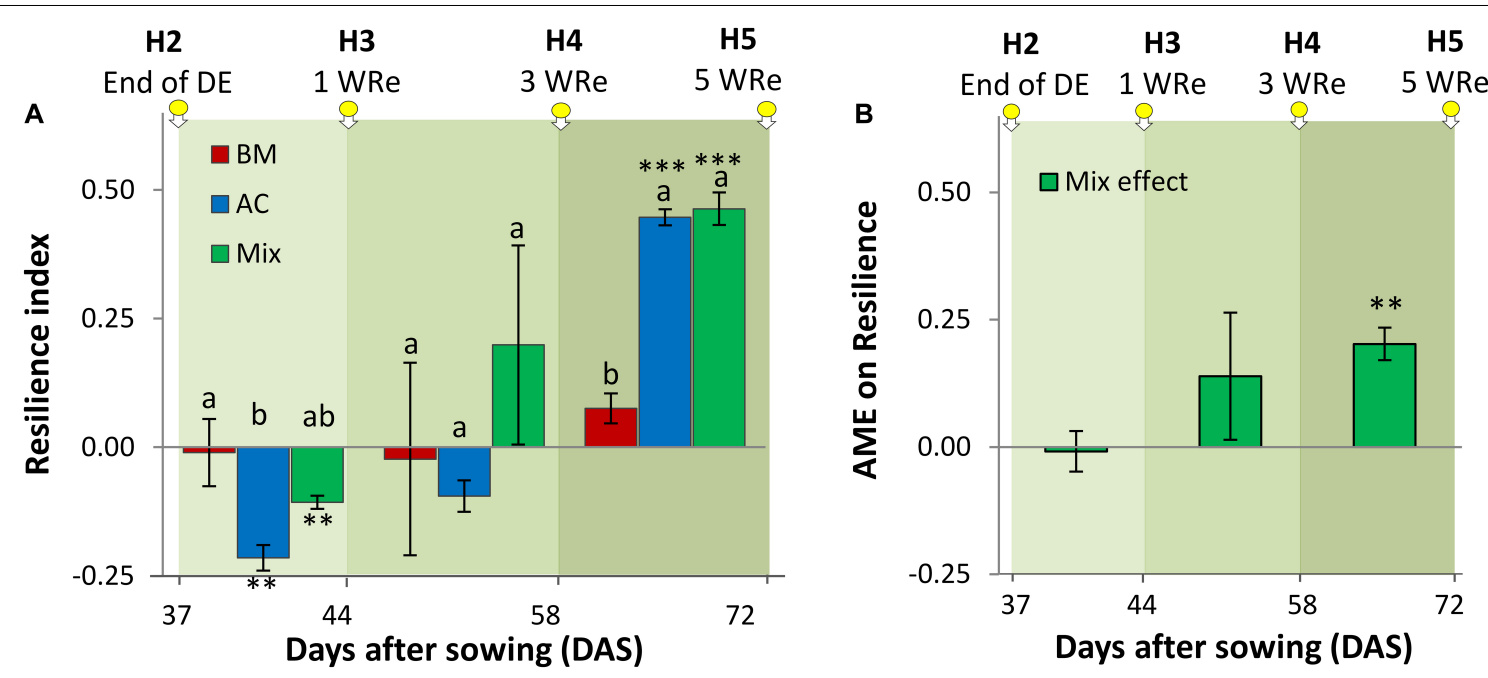

FIGURE 5 | Resilience index calculated to alsike clover (AC), black medic (BM), and a 1:1 mixture of the two species (Mix) after recovery from a drought event (A) and absolute mixture effect on resilience (AME; resilience in mixture - average resilience in the monocultures) (B). The three harvest times during the recovery time are indicated by the downward arrows tagged with yellow small circles. The green gradient color represents weeks of recovery (WRe) after rewatering. The vertical bars represent the standard error. Different letters above the vertical bars indicate significant differences among the three treatments at a given harvest based on ANOVA followed by Tukey's HSD test $(p<0.05)$. Asterisks indicate significant resilience in comparison with 0 according to Welch's $t$-test at $p<0.05$.

species stands. During the drought event, stressed plants will be reduced in their growth in comparison to the non-stressed plants. Therefore, after cessation of the drought more resources (e.g., nutrients) will remain for the stressed than for the nonstressed plants. In effect, this leads to an apparent "recovery" of the stressed plants.

Further, we observed a strong effect of species identity on drought resilience, with a fuller recovery in $\mathrm{AC}$ than in $\mathrm{BM}$ (Figure 5A). The two species showed asynchronous behavior, as $\mathrm{BM}$ recovered faster, while $\mathrm{AC}$ recovered later (Figure $4 \mathrm{~F}$ ). This also means that different aspects of resilience may trade off: recovery tended to be faster in $\mathrm{BM}$, but was achieved to a fuller degree in AC. Our observations confirm BM as a relative fast-growing species (Döring et al., 2013; Elsalahy et al., 2019; FAO, 2019), and AC as growing more slowly (Elsalahy et al., 2019). While fast-growing species do not build large reserves for later growth (Diaz and Cabido, 2001; Hoover et al., 2014), slow-growing species have low demands at the early stages and therefore are less likely to exhaust limiting resources (Poorter, 1989). The fact that $\mathrm{AC}_{\text {mono }}$ recovered more fully from the drought event than BM (Figure 5A) may also be explained by the difference in growth dynamics, as the slow-growing AC may have built more reserves for later growth (Poorter, 1989). In the drought resilience experiment, $\mathrm{AC}_{\text {mono }}$ was more affected by the drought than $\mathrm{BM}_{\text {mono }}$ shortly after the drought event, but later $\mathrm{AC}_{\text {mono }}$ became resilient via a strategy of slow recovery that contributed to significantly larger CCB, WUE, and CGR than observed in BM (Figures $\mathbf{4 D - F}$ ). This is in contrast to the finding that slow species tend to have high resistance but low resilience as they recover slowly and therefore, cannot restore productivity (Diaz and Cabido, 2001; Oliver et al., 2015; Hofer et al., 2016; Craven et al., 2018), while mixtures dominated by fast-growing species tend to have high recovery and resilience but low resistance (Diaz and Cabido, 2001; Hoover et al., 2014; Craven et al., 2018).

The combination of fast-slow dynamics may stabilize biomass production in response to drought as it generates differences in the peak biomass at different dates (Loreau and de Mazancourt, 2013) and may play a role in drought resilience. The fastgrowing species use an exploitative strategy to acquire resources and therefore govern faster recovery, while the slow-growing species use a conservative strategy to tolerate stress which may promote resistance but with lower capacity to recover (Oliver et al., 2015). The observed asynchrony between AC and BM may have contributed to the diversity-effect on resilience, as in the mixture asynchronous growth will lead to temporal niche differentiation and reduced interspecific competition, thereby increasing overall productivity. Accordingly, fast-slow functional diversity may be adaptive to environmental perturbations (Bybee-Finley et al., 2016), specifically in equiproportional mixtures (Kirwan et al., 2007).

\section{Transferability of Results}

The results reported in the current study for plants grown in pot experiments, although artificial, gave similar qualitative (direction of the response) and quantitative (absolute biomass) estimates of AC and BM grown in the field (Supplementary Figure S5). In a field experiment on mixing AC and BM (Elsalahy et al., 2019), the experimental conditions were close to the drought resistance experiment at $70 \%$ WHC. In both the field experiment and the greenhouse experiments reported here, the plants were sown in the same year, at the same seed density, soil type, moisture level, and harvested at a similar phenological stage. During the growing season of the field experiment, the plants received $\sim 70 \%$ precipitation of the long-term average (19812010) and produced biomass comparable to that at drought 
intensity 70\% WHC in the pot experiment, suggesting that results of the pot experiments are comparable to field conditions when assessing short-term drought effects on these legume species.

Nevertheless, it is clear that our pot experiments are unable to replicate or represent the complex drought effects on crop yields in agro-ecosystems that are generated by the various interactive drought-related mechanisms, involving the soil as well as biotic factors (Mariotte et al., 2018; Schimel, 2018).

Further, we only used two species in this study, in order to restrict the complexity of the potential interactions and we only varied species richness but not any other aspects of diversity. Therefore, our conclusions on the effect of diversity on resilience and resistance of plants remain limited to this relatively simple set-up. However, the fact that we observed significant resilience to drought in a single-species stand is unaffected by this limitation. Further studies will need to clarify how individual species contribute to resilience in more complex communities, and how large these contributions are in relation to the effect of diversity.

Finally, we acknowledge that the positive effects of species richness under dry conditions, for which our study shows some evidence, will not be sufficient for reducing the large negative impacts of drought on crops.

\section{CONCLUSION}

Our main aim was to quantify the effects of mixing plant species on resistance and resilience to drought. Representing an arable context of a short-term green manure, we chose a basic design, by mixing two species belonging to the same functional group, legumes, and comparing the mixture with the two monocultures of the component species, as is common in intercropping research (Bedoussac et al., 2015). The two legume species differed in their drought resistance and resilience, with $\mathrm{BM}$ being more resistant than $\mathrm{AC}$, while the order was reversed for resilience. Mixing the two species was not more advantageous under constant drought than under fully irrigated conditions, suggesting that species identity was more important than species richness in response to constant drought. However, the mixture was more resilient to a transient drought event than the average of the sole crops. Remarkably, a monoculture of AC was equally resilient to drought as the mixture, indicating that response diversity was not required for the plants to show resilience.

The strong species identity effects on drought resilience in our study suggest that further research is needed to determine drought resistance and resilience in a larger range

\section{REFERENCES}

Agricultural Climatology of the Hu-Berlin (2018). Agricultural Climatology of the Humboldt-University of Berlin. Available online at: https: //www.agrar.hu-berlin.de/de/institut/departments/dntw/agrarmet/service/wo (accessed September 15, 2019).

Allsion, G. (2004). The influence of species diversity and stress intensity on community resistance and resilience. Ecol. Monogr. 74, 117-134.

Barkaoui, K., Roumet, C., and Volaire, F. (2016). Mean root trait more than root trait diversity determines drought resilience in native and cultivated of (agriculturally relevant) plant species, including those grown in arable systems. Also, with the positive effect of mixing species on drought resilience shown in our experiments, there is great potential to apply these findings to other relatively simple (e.g., binary) plant mixtures, possibly adding to the already numerous benefits these mixtures offer for agriculture. Further studies on the physiological mechanisms of resilience to drought in plants will also help to deepen the understanding of the underlying processes.

\section{DATA AVAILABILITY STATEMENT}

All datasets generated for this study are included in the article/Supplementary Material.

\section{AUTHOR CONTRIBUTIONS}

HE and TD conceived and designed the experiments, conducted the experiments, collected the data, wrote the manuscript, and performed the statistical tests. TD provided the facilities and advised on the preparation of materials. SB-K, TK, and C-LR read and edited the manuscript. All authors approved the final manuscript.

\section{FUNDING}

This research was funded by the Jameel Scholarship at HumboldtUniversity, Berlin, Germany [Ph.D. project].

\section{ACKNOWLEDGMENTS}

The Jameel Scholarship at Humboldt University, Berlin, Germany, and the Ekhaga Foundation are greatly appreciated for their financial support. We also thank the staff at the HumboldtUniversity, Department of Agronomy and Crop Science for technical support during the experiments.

\section{SUPPLEMENTARY MATERIAL}

The Supplementary Material for this article can be found online at: https://www.frontiersin.org/articles/10.3389/fpls.2020.00721/ full\#supplementary-material
Mediterranean grass mixtures. Agric. Ecosyst. Environ. 231, 122-132. doi: 10. 1016/j.agee.2016.06.035

Bedoussac, L., Journet, E. P., Hauggaard-Nielsen, H., Naudin, C., Corre-Hellou, G., Jensen, E. S., et al. (2015). Ecological principles underlying the increase of productivity achieved by cereal-grain legume intercrops in organic farming. A review. Agron. Sustain. Dev. 35, 911-935. doi: 10.1007/s13593-014-0277-277

Bhaskar, R., Arreola, F., Mora, F., Martinez-Yrizar, A., Martinez-Ramos, M., and Balvanera, P. (2018). Response diversity and resilience to extreme events in tropical dry secondary forests. For. Ecol. Manage. 426, 61-71. doi: 10.1016/j. foreco.2017.09.028 
Brady, N. C., and Weil, R. R. (2002). The Nature and Properties of Soils, 13th Edn, London: Pearson Education Inc.

Burnham, K. P., Anderson, D. R., and Huyvaert, K. P. (2011). AIC model selection and multimodel inference in behavioral ecology: some background, observations, and comparisons. Behav. Ecol. Sociobiol. 65, 23-35. doi: 10.1007/ s00265-010-1029-1026

Bybee-Finley, K. A., Mirsky, S. B., and Ryan, M. R. (2016). Functional diversity in summer annual grass and legume intercrops in the northeastern United States. Crop Sci. 56, 2775-2790. doi: 10.2135/cropsci2016.01.0046

Chapman, H. M., Dodds, K. G., and Keoghan, J. M. (1990). Evaluation of the agronomic potential of pasture legume introductions on droughty outwash soils. New Zeal. J. Agric. Res. 33, 21-27. doi: 10.1080/00288233.1990.10430657

Craven, D., Eisenhauer, N., Pearse, W. D., Hautier, Y., Isbell, F., Roscher, C., et al. (2018). Multiple facets of biodiversity drive the diversity-stability relationship. Nat. Ecol. Evol. 2, 1579-1587. doi: 10.1038/s41559-018-0647-647

De Mendiburu, F. (2019). Agricolae: Statistical Procedures for Agricultural Research. $R$ Package Version 1.3-0. Available online at: https:/CRAN.R-project.org/ package $=$ agricolae $($ accessed September 15, 2019).

Di Falco, S., and Chavas, J. P. (2008). Rainfall shocks, resilience, and the effects of crop biodiversity on agroecosystem productivity. Land Econ. 84, 83-96. doi: $10.3368 /$ le.84.1.83

Diaz, S., and Cabido, M. (2001). Plant functional diversity matters to ecosystem processes. Trends Ecol. Evol. 16, 646-655.

Döring, T. F., Baddeley, J. A., Brown, R., Collins, R., Crowley, O., Cuttle, S., et al. (2013). Using legume-based mixtures to enhance the nitrogen use efficiency and economic viability of cropping systems: project report (RD-2007-3447). HGCA Agric. Hort. Dev. Board. 190:25. doi: 10.1016/j.talanta.2010.11.025

Elmqvist, T., Folke, C., Nyström, M., Peterson, G., Bengtsson, J., Walker, B., et al. (2003). Response diversity, ecosystem change, and resilience. Front. Ecol. Environ. 1, 488-494. doi: 10.1890/1540-92952003001[0488:RDECAR]2.0.CO;2

Elsalahy, H., Döring, T., Bellingrath-Kimura, S., and Arends, D. (2019). Weed suppression in only-legume cover crop mixtures. Agronomy 9:648. doi: 10.3390/ agronomy 9100648

FAO (2019). Ecocrop, Data Sheet, Black Medic (Medicago Lupulina). Rome: FAO.

Fischer, F. M., Wright, A. J., Eisenhauer, N., Ebeling, A., Roscher, C., Wagg, C., et al. (2016). Plant species richness and functional traits affect community stability after a flood event. Philos. Trans. R. Soc. B Biol. Sci. 371:276. doi: 10.1098/rstb. 2015.0276

Fleta-Soriano, E., and Munné-Bosch, S. (2016). Stress memory and the inevitable effects of drought: a physiological perspective. Front. Plant Sci. 7:143. doi: 10.3389/fpls.2016.00143

Floulds, W. (1978). Response to soil moisture supply in three leguminous species: i. growth, reproduction and mortality. New Phytol. 80, 535-545. doi: 10.1111/j. 1469-8137.1978.tb01585.x

Frankow-Lindberg, B. E., Halling, M., Höglind, M., and Forkman, J. (2009). Yield and stability of yield of single- and multi-clover grass-clover swards in two contrasting temperate environments. Grass Forage Sci. 64, 236-245. doi: 10. $1111 /$ j.1365-2494.2009.00689.x

Grossiord, C., Granier, A., Ratcliffe, S., Bouriaud, O., Bruelheide, H., Chećko, E., et al. (2014). Tree diversity does not always improve resistance of forest ecosystems to drought. Proc. Natl. Acad. Sci. U.S.A. 111, 14812-14815. doi: 10.1073/pnas. 1411970111

Hodgson, D., McDonald, J. L., and Hosken, D. J. (2015). What do you mean, "resilient"? Trends Ecol. Evol. 30, 503-506. doi: 10.1016/j.tree.2015.06.010

Hofer, D., Suter, M., Haughey, E., Finn, J. A., Hoekstra, N. J., Buchmann, N., et al. (2016). Yield of temperate forage grassland species is either largely resistant or resilient to experimental summer drought. J. Appl. Ecol. 53, 1-11. doi: 10.1111/ 1365-2664.12694

Hoover, D. L., Knapp, A. K., and Smith, M. D. (2014). Resistance and resilience of a grassland ecosystem to climate extremes. Ecology 95, 2646-2656. doi: 10.1890/ 13-2186.1

Huang, Y., Gerber, S., Huang, T., and Lichstein, J. W. (2016). Evaluating the drought response of CMIP5 models using global gross primary productivity, leaf area, precipitation, and soil moisture data. Glob. Biogeochem. Cycles 30, 1827-1846. doi: 10.1002/2016GB005480

Hutchison, C., Gravel, D., Guichard, F., and Potvin, C. (2018). Effect of diversity on growth, mortality, and loss of resilience to extreme climate events in a tropical planted forest experiment. Sci. Rep. 8, 1-10. doi: 10.1038/s41598-01833670-x
IPCC (2013). "Summary for policymakers," in Climate Change 2013: the Physical Science Basis. Contribution of Working Group I to the Fifth, eds T. F. Stocker, D. Qin, G. K. Plattner, M. Tignor, S. K. Allen, J. Boschung, et al. (Geneva: IPCC).

John, F., and Weisberg, S. (2011). An $\{R\}$ Companion to Applied Regression, 2nd Edn, Thousand Oaks CA: Sage.

Kirwan, L., Lüscher, A., Sebastià, M. T., Finn, J. A., Collins, R. P., Porqueddu, C., et al. (2007). Evenness drives consistent diversity effects in intensive grassland systems across 28 European sites. J. Ecol. 95, 530-539. doi: 10.1111/j.1365-2745. 2007.01225.x

Komainda, M., Küchenmeister, K., Küchenmeister, F., Breitsameter, L., WrageMönnig, N., Kayser, M., et al. (2019). Forage legumes for future dry climates: lower relative biomass losses of minor forage legumes compared to Trifolium repens under conditions of periodic drought stress. J Agro Crop Sci. 20, 460-469. doi: $10.1111 /$ jac. 12337

Lanta, V., Doležal, J., Zemková, L., and Lepš, J. (2012). Communities of different plant diversity respond similarly to drought stress: experimental evidence from field non-weeded and greenhouse conditions. Naturwissenschaften 99, 473-482.

Loreau, M., and de Mazancourt, C. (2008). Species synchrony and its drivers: neutral and nonneutral community dynamics in fluctuating environments. Am. Nat. 172, E48-E66. doi: 10.1086/589746

Loreau, M., and de Mazancourt, C. (2013). Biodiversity and ecosystem stability: a synthesis of underlying mechanisms. Ecol. Lett. 16, 106-115. doi: 10.1111/ele. 12073

Mariotte, P., Mehrabi, Z., Bezemer, T. M., De Deyn, G. B., Kulmatiski, A., Drigo, B., et al. (2018). Plant-soil feedback: bridging natural and agricultural sciences. Trends Ecol. Evol. 33, 129-142. doi: 10.1016/j.tree.2017.11.005

Mariotte, P., Vandenberghe, C., Kardol, P., Hagedorn, F., and Buttler, A. (2013). Subordinate plant species enhance community resistance against drought in semi-natural grasslands. J. Ecol. 101, 763-773. doi: 10.1111/1365-2745.12064

Mead, R., and Willey, R. W. (1980). The concept of a 'land equivalent ratio' and advantages in yields from intercropping. Exp. Agric. 16, 217-228. doi: 10.1017/ S0014479700010978

Mori, A. S., Furukawa, T., and Sasaki, T. (2013). Response diversity determines the resilience of ecosystems to environmental change. Biol. Rev. 88, 349-364. doi: $10.1111 /$ brv.12004

Morin, X., Fahse, L., de Mazancourt, C., Scherer-Lorenzen, M., and Bugmann, H. (2014). Temporal stability in forest productivity increases with tree diversity due to asynchrony in species dynamics. Ecol. Lett. 17, 1526-1535. doi: 10.1111/ ele. 12357

Navarro-Cerrillo, R. M., Rodriguez-Vallejo, C., Silveiro, E., Hortal, A., PalaciosRodríguez, G., Duque-Lazo, J., et al. (2018). Cumulative drought stress leads to a loss of growth resilience and explains higher mortality in planted than in naturally regenerated Pinus pinaster stands. Forests 9:358. doi: 10.3390/ f9060358

Nguyen, B. T., and Lehmann, J. (2009). Black carbon decomposition under varying water regimes. Org. Geochem. 40, 846-853. doi: 10.1016/j.orggeochem.2009. 05.004

Oliver, T. H., Heard, M. S., Isaac, N. J. B., Roy, D. B., Procter, D., Eigenbrod, F., et al. (2015). Biodiversity and resilience of ecosystem functions. Trends Ecol. Evol. 30, 1-38. doi: 10.2134/jeq2016.12.0485

Orwin, K. H., and Wardle, D. A. (2004). New indices for quantifying the resistance and resilience of soil biota to exogenous disturbances. Soil Biol. Biochem. 36, 1907-1912. doi: 10.1016/j.soilbio.2004.04.036

Ouédraogo, D. Y., Mortier, F., Gourlet-Fleury, S., Freycon, V., and Picard, N. (2013). Slow-growing species cope best with drought: evidence from longterm measurements in a tropical semi-deciduous moist forest of Central Africa. J. Ecol. 101, 1459-1470. doi: 10.1111/1365-2745.12165

Pinheiro, J., Bates, D., DebRoy, S., Sarkar, D., and R Core Team (2018). Nlme: Linear and Nonlinear Mixed Effects Models_. R Package Version 3.1137. Available online at: https://CRAN.R-project.org/package=nlme (accessed January 2, 2020).

Poorter, H. (1989). Interspecific Variation In Relative Growth Rate: On Ecological Causes And Physiological Consequences. The Hague: Academic Publishing.

R Core Team (2019). Language and Environment For Statistical Computing. Vienna: R Foundation for Statistical Computing.

Schimel, J. P. (2018). Life in dry soils: effects of drought on soil microbial communities and processes. Annu. Rev. Ecol. Evol. Syst. 49, 409-432. doi: 10. 1146/annurev-ecolsys-110617-162614 
Schwinning, S., and Weiner, J. (1998). Mechanisms determining the degree of size asymmetry in competition among plants. Oecologia 113, 447-455. doi: 10.1007/s004420050397

Sheaffer, C. C., Ehlke, N. J., Albrecht, K. A., and Peterson, P. R. (2003). Forage Legumes: Clovers, Birdsfoot Trefoil, Cicer Milkvetch, Crownvetch and Alfalfa, 2 nd Edn, Saint Paul, MN: Agricultural Experiment Station.

Stagnari, F., Maggio, A., Galieni, A., and Pisante, M. (2017). Multiple benefits of legumes for agriculture sustainability: an overview. Chem. Biol. Technol. Agric. 4, 1-13. doi: 10.1186/s40538-016-0085-81

Storkey, J., Döring, T., Baddeley, J., Collins, R., Roderick, S., Stobart, R., et al. (2015). A framework for designing multi-functional cover crops. Asp. Appl. Biol. 129, 7-12.

Swemmer, A. M., Knapp, A. K., and Snyman, H. A. (2007). Intra-seasonal precipitation patterns and above-ground productivity in three perennial grasslands. J. Ecol. 95, 780-788. doi: 10.1111/j.1365-2745.2007.01237.x

Tilman, D., and Downing, J. A. (1994). Biodiversity and stability in grasslands. Nature 367, 363-365. doi: 10.1038/367363a0

Van Peer, L., Nijs, I., Bogaert, J., Verelst, I., and Reheul, D. (2001). Survival, gap formation, and recovery dynamics in grassland ecosystems exposed to heat extremes: the role of species richness. Ecosystems 4, 797-806. doi: 10.1007/ s10021-001-0047-47
Van Ruijven, J., and Berendse, F. (2010). Diversity enhances community recovery, but not resistance, after drought. J. Ecol. 98, 81-86. doi: 10.1111/j.1365-2745. 2009.01603.x

Yachi, S., and Loreau, M. (1999). Biodiversity and ecosystem productivity in a fluctuating environment: the insurance hypothesis. Proc. Natl. Acad. Sci. U.S.A. 96, 1463-1468. doi: 10.1073/pnas.96.4.1463

Yu, Y., Makowski, D., Stomph, T. J., and van der, W. (2016). Robust increases of land equivalent ratio with temporal niche differentiation: a meta-quantile regression. Agron. J. 108, 2269-2279. doi: 10.2134/agronj2016.03.0170

Conflict of Interest: The authors declare that the research was conducted in the absence of any commercial or financial relationships that could be construed as a potential conflict of interest.

Copyright (c) 2020 Elsalahy, Bellingrath-Kimura, Roß, Kautz and Döring. This is an open-access article distributed under the terms of the Creative Commons Attribution License (CC BY). The use, distribution or reproduction in other forums is permitted, provided the original author(s) and the copyright owner(s) are credited and that the original publication in this journal is cited, in accordance with accepted academic practice. No use, distribution or reproduction is permitted which does not comply with these terms. 